A STUDY OF DEFORMATION AHD FATIGUE OF 316 STAINLESS STEEL AT ROON TEMPERATURE BY POSITRON AKHIHILATIOH

H. B. Gauster, W. R.Wampler, H. B. Jones and

J. A. Van Den Ayyle

Prepared for

U. S. HUCLEAR REGULATORY COHMISSION

Sandia Laboratories 


$$
\begin{gathered}
\text { NUREG } / C R-0118 \\
\text { SAND } 77-1570 \\
R-7
\end{gathered}
$$

\title{
A STUDY OF DEFORMATION AND FATIGUE OF 316 STAINLESS STEEL AT ROOM TEMPERATURE BY POSITRON ANNIHILATION
}

\author{
W. B. Gauster \\ W. R. Wampler \\ W. B. Jones \\ J. A. Van Den Avyle
}

Manuscript Submitted: May, 1978

Date Published: May, 1978

Sandia Laboratories

A) buquerque, New Mexico 87185

operated by

Sandia Corporation

for the

U. S. Department of Energy

$$
\begin{aligned}
& \text { Prepared for } \\
& \text { Diylsion of Reactor Safety Research } \\
& \text { Office of Nuclear Regulatory Research } \\
& \text { U. S. Nuclear Regulatory Commission } \\
& \text { Washington, DC 20555 } \\
& \text { Under Interagency Agreement DOE 40-550-75 } \\
& \text { NRC FIN No. Aliti2 }
\end{aligned}
$$




\section{ABSTRACT}

Scoping studies have been initiated to evaluate the potential of positron annihilation as a volumetric nondestructive examination technique. The first experiments have shown that positron annihilation provides a sensitive monitor of plastic deformation caused by cold rolling and of fatigue cycling of 316 stainless steel at room temperature. Transmission electron microscopy examination of the fatigued samples has shown a direct relationship between dislocation density and the positron annthilation measurements. The effects of changing the strain amplitude of the fatigue cycling are also observed to be significant. The goal of these studies is to determine the positron annihilation response to high temperature creep and creep/fatigue damage encountered in advanced nuclear reactor components. 


\section{A STUDY OF DEFORMATION AND FATIGUE OF 316 STAINLESS}

STEEL AT ROOM TEMPERATURE BY POSITRON ANNIHILATION

\section{INTRODUCTION}

This report describes work performed as part of an ongoing contract with the Nuclear Regulatory Commisston entitled "Elevated Temperature Destgn Assessment" (Contract 189 A 1172). The purpose of the project is to quantify elevated temperature failure modes for materials used in advanced high temperature reactor primary and secondary cooling loop components. This quantification is being attempted by using physical measurements of materlals damaged at room and elevated temperatures; these measurements include both destructive and nondestructive methods. The ultimate goal is the development of volumetric nondestructive examination (NDE) techniques which can be used as an Inservice inspection technique to monttor microstructural changes and, in turn, be correlated to creep and creep/fatigue damage.

A new NDE method for studying internal defect structures in metals is positron annihilation (PA). 1-3 This technique has been used successfully to measure dislocation density changes in several cold worked materials, ${ }^{4-7}$ and appears attractive as a method to follow microstructural changes induced by high temperature deformation. In this report, the results of several scoping experiments to assess the technique are presented.

In these experiments an existing PA apparatus was employed, requiring the use of small sectioned wafers as specimens. In this sense, the experiments done here were not nondestructive. 
However, as outifined in section VI, a test apparatus is now under development with which measurements will be made on mechanfcal test specinens directly without sectioning.

The primary questions addressed were ones involving (1) specimen preparation, (2) experimental sensitivity, and (3) data reproducibility. It was decided to conduct this initial series of scoping tests on room temperature deformed specimens of 316 stainless steel. This is a widely used alloy which is ASME code qualified for high temperature structural applications. Specimens were deformed by efther cold roliting to increasing percentages of cold work or fatiguing to several different fractions of the specimen $11 f$ e. PA and microhardness measurements were performed along with transmisston electron microscopy (TEM). Correlations between PA results and TEM observations are discussed.

II. SAMPLE MATERIAL, PREPARATION, AND MECHANICAL TESTING

The 316 stainless steel specimens for both fatigue tests and cold rolling were cut from a $122 \mathrm{~cm} \times 122 \mathrm{~cm} \times 2.54 \mathrm{~cm}$ plate obtained from Oak Ridge National Laboratory. The plate was produced by Republic Steel Corporation as Heat No. 8092297; its chemistry is listed in Table I. The material as received had been mill-annealed. To assure uniformity and to remove some of the surface cold work caused by machining, one set of cold rolling samples was reannealed in vacuum at $1338 \mathrm{~K}$ for one hour. Following the anneal, the samples were cooled rapidly in flowing argon gas. 
Table I. Chemistry of 316 Stafnless Steel (Republic Steel Company, Cleveland, Ohto, Heat Number 8092297).

\begin{tabular}{|c|c|}
\hline Element & Weight Percent \\
\hline C & 0.059 \\
\hline Mn & 1.86 \\
\hline $\mathbf{p}$ & 0.024 \\
\hline $\mathbf{S}$ & 0.018 \\
\hline Si & 0.57 \\
\hline $\mathrm{Cu}$ & 0.10 \\
\hline $\mathrm{NI}$ & 13.45 \\
\hline Cr & 17.15 \\
\hline Mo & 2.34 \\
\hline Tt & 0.00 \\
\hline Co & 0.02 \\
\hline $\mathbf{H}$ & 0.031 \\
\hline $\mathbf{B}$ & 0.0005 \\
\hline $\mathrm{Hb}+\mathrm{Ta}$ & 0.00 \\
\hline $\mathrm{Fe}$ & rest \\
\hline
\end{tabular}


For cold rolling experiments, specimens were saw-cut from the plate with the rolling directions of the specimens parallel to the rolling direction of the plate. Dimensions were $2.5 \mathrm{~cm} \times$ $10.0 \mathrm{~cm} \times 0.3 \mathrm{~cm}$. Both annealed and as-cut samples were rolled to five levels of cold work, as shown in Table II. Percent cold work was defined as the percentage reduction in thickness.

Low cycle fatigue test specimens were machined with a straight-sided gauge section $1.90 \mathrm{~cm}$ long by $0.64 \mathrm{~cm}$ diameter. Testing was performed on an MTS Systems Corporation hydraulic loading frame with samples under axial strain control using a $1.27 \mathrm{~cm}$ gauge length extensometer. Load-total strain hysteresis loops were plotted on an $X-Y$ recorder to monitor the cyclic strain hardening behavior. Tests were conducted at cyclic total strain amplitudes of $\pm 0.90 \%$ and $\pm 0.30 \%$ at a frequency of $0.4 \mathrm{~Hz}$. After cold rolling or cycling, samples were cut for PA and microhardness measurements. A slow-speed sut-off wheel was used to slice $0.13 \mathrm{~cm}$ sections which, for the fatigued material, were normal to the specimen axis. In each case, two silces were electropolished for PA measurements. A third slice was mounted and polished for microhardness measurements using a knoop indenter with a $100 \mathrm{gmin}$ load.

The electropolishing of the PA samples was done in a solution of 1 part $\mathrm{HNO}_{3}, 1$ part $\mathrm{H}_{2} \mathrm{O}$, and 9 parts methyl alcohol (by yolume) at temperatures between $223 \mathrm{~K}$ and $213 \mathrm{~K}$ and an applied voltage of $30 \mathrm{~V}$. A $125 \mu \mathrm{m}$ layer was taken from each side to remove the surface material that had been mechanically damaged during the sectioning of the samples. 
Table II. Listing of Cold-Rolled 316 Stainless Steel Specimens (3)6-CR-AR-1 to 5: as received; $316-C R-A N-1$ to 5: annealed after machining of samples prior to rolling; see text for detailst.

\begin{tabular}{|c|c|c|c|}
\hline Specimen & $\begin{array}{c}t_{0} \\
(\mathrm{~cm})\end{array}$ & $\begin{array}{c}\mathbf{t}_{\mathbf{f}} \\
(\mathrm{cm})\end{array}$ & $\begin{array}{l}\% \text { Cold Work } \\
\frac{t_{0}-t_{f}}{t_{0}} \times 100\end{array}$ \\
\hline $316-C R-A R-1$ & 0.318 & 0.305 & 4.1 \\
\hline $316-C R-A R-2$ & 0.318 & 0.283 & 11.0 \\
\hline $316-C R-A R-3$ & 0.318 & 0.246 & 22.6 \\
\hline $316-C R-A R-4$ & 0.318 & 0.175 & 45.0 \\
\hline $316-C R-A R-5$ & 0.318 & 0.081 & 74.5 \\
\hline $316-C R-A N-1$ & 0.312 & $0.30 i$ & 3.5 \\
\hline $316-C R-A N-2$ & 0.312 & $0.28 i$ & 9.6 \\
\hline $316-C R-A N-3$ & 0.312 & 0.234 & 25.0 \\
\hline $316-C R-A N-4$ & 0.312 & 0.155 & 50.3 \\
\hline $316-C R-A N-5$ & 0.312 & 0.079 & 74.7 \\
\hline
\end{tabular}


Sections for transmission electron microscopy (TEM) were spark cut normal to the fatigue specimen axes and mechantcally polished to a thickness of $0.013 \mathrm{~cm}$. Disks were punched out and electropolished using the jet technique. The solution used was 59\% (by volume) methyl alcohol, 35\% butyl cellusolve, and 6\% perchloric acid; conditions were $12 \vee$ at $273 \mathrm{~K}$.

\section{I. POSITRON ANNIHILATION TECHNIQUE AND MEASUREMENTS}

There is extensive experimental evidence that positron annihilation in solids is sensitive to defects.1,2,3 Certain characteristics of the $\gamma$-radiation which results from positronelectron annihilation depend strongly on the concentration of vacanctes or other "open-volume" defects in metal samples, such as dislocation cores. The PA technique is being used widely in fundamental defect studies and there is increasing interest in its application as a NDE too 1.6

Positrons are most commoniy obtained from sources external to the sample under study. Sultable emitters are produced in a variety of reactions and are commerctally available. The positrons emitted have a distribution of energies up to a maximum value that determines their deepest penetration in a metal.

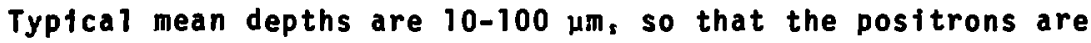
implanted in the bulk of the samples. Table III is a listing of the most commonly used source isotopes, together with the production reactions, the half-ifues of the resulting nuclef and the maximum energies of the emitted positrons. 
Table III. Isotopes used as positron sources, with their half liyes, production reactions, and positron endpoint energies.

\begin{tabular}{|c|c|c|c|}
\hline Isotope & Half-life & $\begin{array}{c}\text { Positron } \\
\text { end-point energy } \\
E_{\max }(\mathrm{MeV})\end{array}$ & $\begin{array}{l}\text { Production } \\
\text { reactions }\end{array}$ \\
\hline $22 \mathrm{Na}$ & $2.58 \mathrm{yr}$ & 0.54 & ${ }^{25} \mathrm{Mg}(p, \alpha)^{22} \mathrm{Na}$ \\
\hline${ }^{44} \mathrm{Ti} / /^{44} \mathrm{SC}$ & $47 \mathrm{yr}$ & 1.47 & ${ }^{* 2} \mathrm{Ca}(\alpha, 2 n) * 4 \mathrm{Ti}$ \\
\hline${ }^{5} \mathrm{Co}$ & $18.2 h$ & 1.50 & $\begin{array}{l}5 \mathrm{NA}(p, \alpha)^{55} \mathrm{Co} \\
56 \mathrm{Fe}(p, 2 n)^{55} \mathrm{Co}\end{array}$ \\
\hline $57 N 1$ & $36.0 \mathrm{~h}$ & 0.85 & $56 \mathrm{Fe}\left({ }^{3} \mathrm{He}, 2 \mathrm{n}\right)^{57 \mathrm{NI}}$ \\
\hline saco & 71.3 days & 0.48 & $\begin{array}{l}5{ }^{\circ} \mathrm{Ni}(n, p){ }^{50} \mathrm{Co} \\
{ }^{5} \mathrm{Mn}(\alpha, n)^{50} \mathrm{Co}\end{array}$ \\
\hline${ }^{64} \mathrm{Cu}$ & $12.9 \mathrm{~h}$ & 0.65 & ${ }^{63} \mathrm{Cu}(n, \gamma){ }^{64} \mathrm{Cu}$ \\
\hline $65 \mathrm{Zn}$ & 245 days & 0.33 & $64 \mathrm{Zn}(n, \gamma)^{65} \mathrm{Zn}$ \\
\hline $60 \mathrm{Ge} /{ }^{\circ} \mathrm{Ga}$ & 275 days & 1.88 & ${ }^{6} \mathrm{Zn}^{\mathrm{Z}}(\alpha, 2 \mathrm{Z})^{6} \cdot \mathrm{Ge}$ \\
\hline $69 \mathrm{Ge}$ & $40 h$ & 1.22 & ${ }^{69} \mathrm{Ga}(d, 2 \mathrm{n})^{69} \mathrm{Ge}$ \\
\hline SONb & $14.7 h$ & 1.50 & $\begin{array}{rl}90 & Z r(p, n) 90 \mathrm{Nb}, \\
& 90 \mathrm{Zr}(d, 2 \mathrm{~d}) 90 \mathrm{Nb}\end{array}$ \\
\hline
\end{tabular}


Positrons entering a metal rapidly lose most of their kinetic energy by collisions with ions and electrons, and finally phonons, reaching thermal velocities in a few times $10^{-12} \mathrm{~s}$. Being antiparticles of electrons, positrons will annihilate with electrons, most commoniy in a $2 \gamma$ process, after a lifetime of typically several $10^{-10} \mathrm{~s}$ in a metal. Coulomb interactions repel the positrons from positive ion cores, so that they annihilate primarily with conduction electrons. The positrons themselves occuny states at the bottom of the positron conduction band at the time of decay. In detailed discussions of the annihilation characteristics, the charge screening around the positrons plays an important role.

For some purposes it is useful to represent the behavior of the thermalized positron as diffusion, without specifying the microscopic processes. Then it can be shown theoretically that the positron will cover a distance of the order of $10^{3} \AA$ in its lifetime, which gives a measure of the volume it samples before annihilating. If it encounters a lattice defect in this yolume and is trapped there, the annihilation radiation will yield information about the altered electron density and momentum distribution at the defect.

Let $\gamma_{f}(\vec{p}) d^{3} \vec{p}$ equal the probability of annihilation with the $i^{\text {th }}$ electron, for a photon peir momentum in $d^{3} \vec{p}$ about $\vec{p}$ (two-photon annihilation). If $\Psi_{j}(\vec{r})$ is the wave function of the $i^{\text {th }}$ electron and $\Psi_{+}(\vec{r})$ is the wavefunction of the positron, then 


$$
\gamma_{i}(\vec{p}) d^{3} \vec{p}=\frac{\pi r_{0}^{2} c}{(2 \pi)^{3}}\left|\int_{j}(\vec{r}) \Psi_{+}(\vec{r}) e^{-i \vec{p} \cdot \vec{r}}\right|^{2} d^{3 \vec{r}},
$$

where $r_{0}$ is the classical electron radius and $c$ the speed of light. The total annihilation rate (or reciprocal positron lifetime) is obtained by summing over all occupied electron states and photon momenta:

$$
\Gamma=\sum_{i} \Gamma_{i}=\sum_{i} \int \gamma_{i}(\vec{p}) d^{3} \vec{p}
$$

Because the positron occupies its lowest energy state, its contribution to the total momentum is negligible. Thus $\Gamma$ depends primarily on the momentum distribution of the electrons at the site of decay, and that is the key to the utility of the positron annihilation technique.

If the positron and the electron with which it annihilates were both at rest at the time of decay, the two $r$ 's emitted would be at exactly $180^{\circ}$ with respect to each other in order to conserve momentum. Each would have an energy of $511 \mathrm{keV}$, the rest energy of an electron and of a positron. In fact, however, the positron is essentially at rest but the electron is not. Thus the directions of the $Y^{\prime}$ 's deviate slightly from $180^{\circ}$ by an angle $\theta$. Let the $z$ component of the pair momentum be $p_{z}=\hbar k_{z}$. For small angles $p_{z}=m c \theta$, where $m=$ eleccron mass. The angular correlation counts $N\left(p_{z}\right)$ are given by

$$
N\left(p_{z}\right)=\iint_{-\infty}^{+\infty} \gamma_{f}\left(p_{x}, p_{y}, p_{z}\right) d p_{x} d p_{y} .
$$

It is readily shown that for a spherical Fermi surface (freeelectron approximation), the resulting distribution is an 
Inverted paraboia. In metals the measured distribution consists of this parabolic part, referred to as the conduction electron contribution, superimposed on a broader portion going to higher momenta and often represented by a Gausian function. Most of the latter is atributed to the overlap of positron wavefunctions with the wavefunctions of tightly bound electrons and is referred to as the core contribution.

Angular correlation measurements can be done to measure $M\left(p_{z}\right)$ with high precision. The apparatus is somewhat cumbersome, however, and counting times of the order of days are raquired. For MDE applications, the technique of Doppler broadening measurements is more sultable. Although the resolution is not as good as with angular correlation, the apparatus is less cumbersome and can even be made portable. In addition, counting times of oniy an hour are now required to obtain good statistics, and with fimprovements in technology it may well be possible to reduce these times considerably.

Doppler broadening measurements are accomplished by looking at the annihllation photons head-on with an energy resolving detector. How the electron momenium component $\left(p_{x}\right)$ parallel to the direction of the emitted photon is resolved, rather than the perpendicular component $\left(p_{z}\right)$ measured by angular correlation. If $E_{0}=511 \mathrm{keV}$ is the rest energy and $m_{0}$ the rest mass of the electron,

$$
E=E_{0} \pm \Delta E=m_{0} c^{2} \pm(c / 2) p_{x} \text {, if } v \ll c \text {. }
$$

For an electron energy of $10 \mathrm{eV}$, the order of magnitude of the Fermi energy, $2 \Delta \mathrm{E}=3 \mathrm{keV}$. The best resolution of $\mathrm{Ge}(\mathrm{LI})$ 
detectors is about $1.1 \mathrm{keV}$ at $511 \mathrm{keV}$, so the momentum resolution $p_{X} \& 1 / 3 k_{F}$. In angular correlation experiments an order of magnttude better resolution is readily obtained. However, the faster data acquisition rate and flexible geometry of the Doppler measurement apparatus more than compensate for the lifited resolution in practical situations.

It has been determined experimentally that the Doppler broadened lineshape becomes more sharply peaked with increasing defect concentratiol. The effect begins for atomic concentrations of defects between $10^{-7}$ and $10^{-6}$, and saturation occurs for concentrations of approximately $10^{-4}$ to $10^{-3}$. These observations are consistent with the picture of positrons being trapped at defects and then anninilating with electrons that have different. momenta in the defect volume than in the undisturbed region of the lattice.

The Doppler broadening apparatus is shown schematically in Figure 1. Note the sample-source "sandwich" configuration, with the source clamped between two pieces of sample material. A more detalled description of the apparatus can be found in reference $B$. The positron source consisted of approximately $30 \mu \mathrm{Cl}$ of ${ }^{22} \mathrm{NaCl}$ and the samples were disks 1-2 $\mathrm{mm}$ thick and $6 \mathrm{~mm}$ in diameter. This geometry assures that almost all positrons emanating from the source are stopped in the samples. The deposition profile is well represented by an exponential dependence inward from the sample surface, and the range of positrons from the source material, ${ }^{22} \mathrm{Ha}$, is such that approximately $2 / 3$ are stopped in a layer of the samples $30 \mu \mathrm{m}$ thick. 
In addition to the apparatus, Figure 1 shows an example of data accumulated in the muttichannel analyzer. On the top is a $514 \mathrm{keV}$ line from a ${ }^{85} \mathrm{Sr}$ reference source that is used to determine the energy resolution of the system. Below is seen a typical Doppler-broadened 511 keV annihilation ine resulting from the annihilation of positrons that have been stopped in a sample. From such records a lineshape parameter was calculated, defined as the number of counts in the center 6 channels divided by the counts in the center 48 channels of the 511 keV annihilation line, multiplied by 100 . The lineshape parameter is simply a conventent representation of the normalized peak height of the line, which, for a Gaussian curye, is inversely proportional to the full width at half maximum. All PA data discussed below will be represented in terms of the lineshape parameter, measured at room temperature, as a function of sample history. An increase of the defect concentration results in a narrowing of the annihilation line, which in turn causes an increase of the lineshape parameter.

The "sandwich" configuration of source and samples results in four possible combinations of pairs of sample surfaces in contact with the source. This potential source of variation was investigated and found not to be significant. It was concluded that the reproducibility of the technique was good since the measured changes of lineshape parameter which occur during the mechanical test are usually more than an order of nignitude greater than any measured variation for a single pair of samples. 


\section{POSITRON ANNIHILATION}

DOPPLER BROADENING

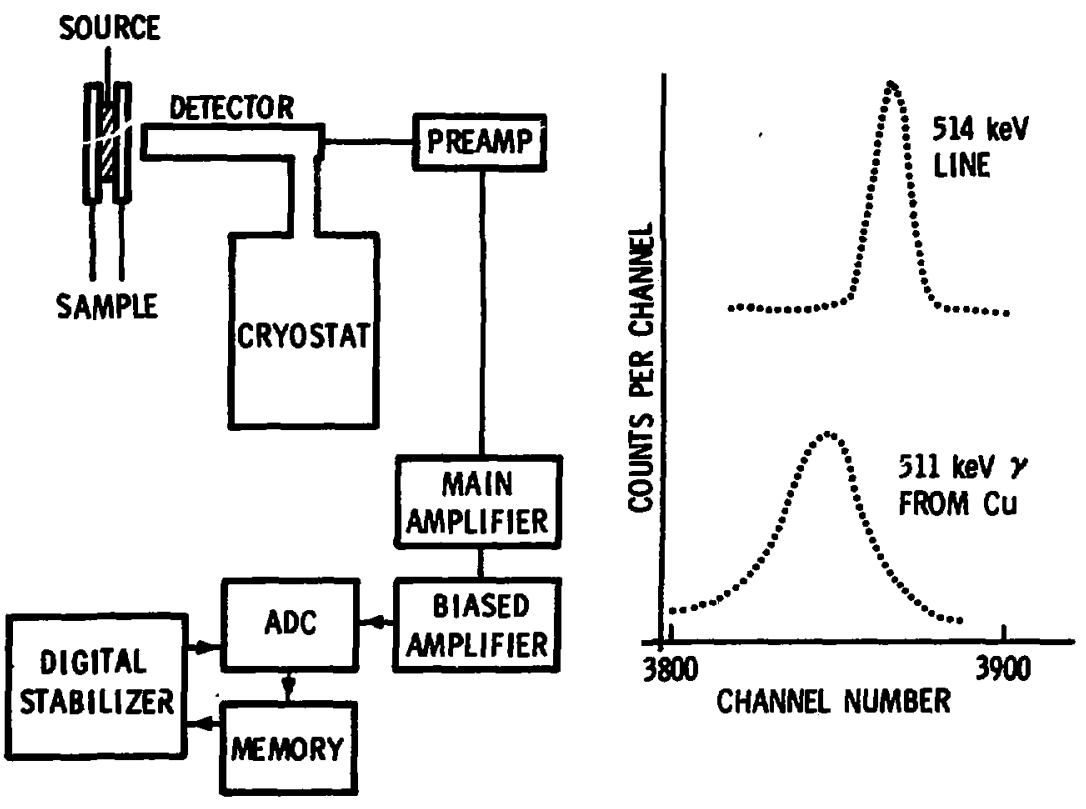

Figure 1. Positron annihilation Doppler-broadening spectrometer arrangement and example of data. 


\section{RESULTS AND DISCUSSION}

\section{A. Importance of surface layer}

The first samples looked at with PA were the cold-rolled 316 stainless steel specimens listed in Table II. Stnce they had been sectioned mechanicaliy and because the range of positrons from ${ }^{22} \mathrm{Na}$ is relatively shallow, it was suspected that a surface layer not necessarily representative of the bulk material would be sampled in the PA measurements. To investigate the surface effect, PA runs were made on each sample, both before and after electropolishing a 125 um layer from the surface.

In addition, the microhardness measurements described in Section II were performed on the same samples. The values of Knoop hardness number are plotted in Figure 2 . It is seen that the values for as-received and annealed samples are for the most part within error bars, indicating that re-annealing the asreceived material had little effect. The microhardness measurements are not expected to be sensitive to whether the surface was electropolished or mechanically polished since the diamond indentor penetrates a few hundred micrometers, which is several orders of magnitude deeper than any surface damage induced by mechanical polishing.

The measured PA lineshape parameter was, however, altered by electropolishing. The sequential etching of $25 \mu \mathrm{m}$ layers from sample surfaces resulted in lineshape parameter value changes when less than $125 \mu \mathrm{m}$ total had been removed. Thus, It was concluded that the removal of $125 \mu \mathrm{m}$ was sufficient to el iminate surface behavior not characteristic of the bulk. The 


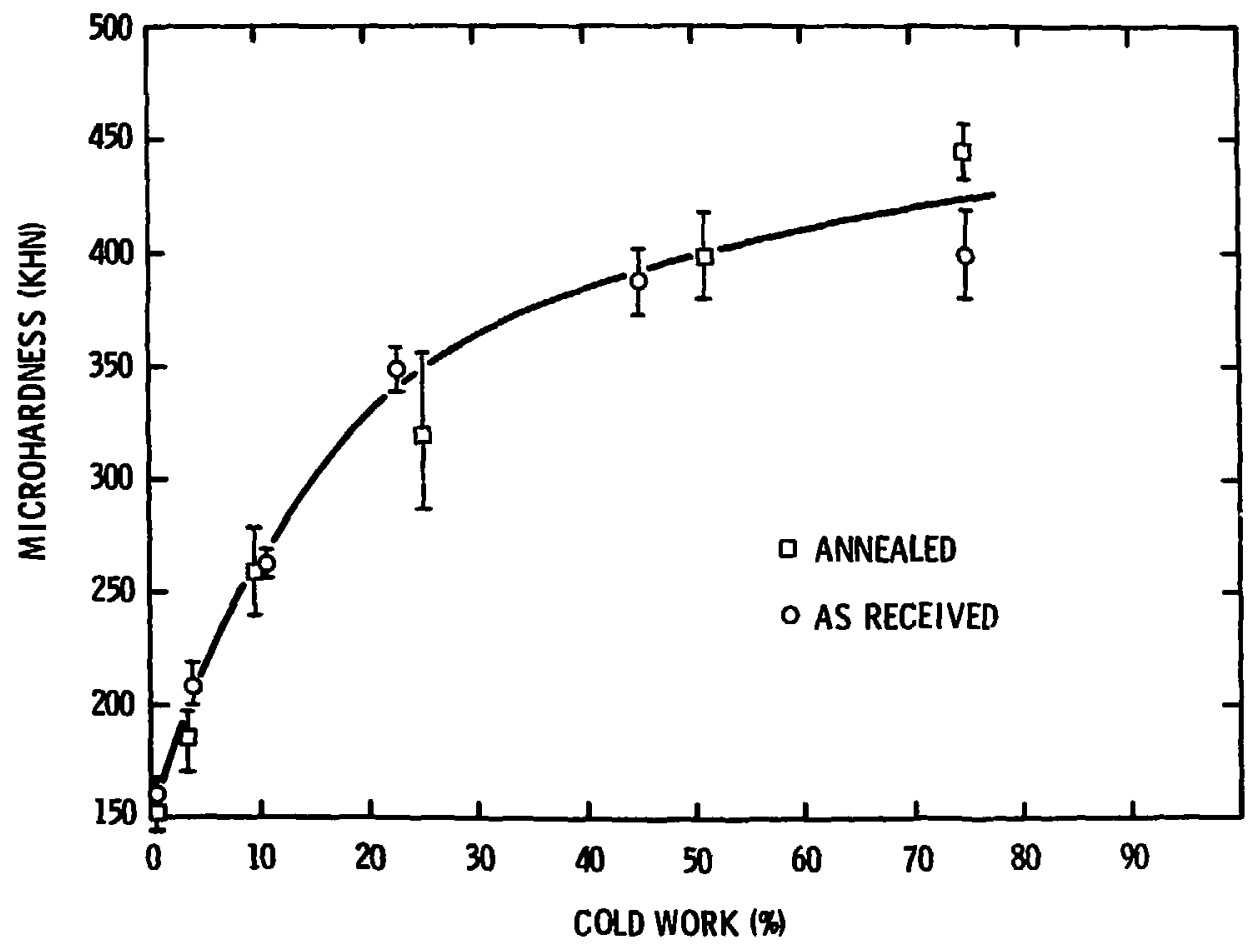

Figure 2. Microhardness in terms of Knoop hardness number (KHN) as a function of percent thickness reduction for the samples 11 sted in Table II. 
magnitude and direction of changes in the PA measurements is sensitive to material history. Figure 3 shows the changes in $P A$ characteristics due to surface layer removal as a function of microhardness after cold rolling. During the rolling process a large amount of deformation occurs at the surface. This highly deformed layer greatly affects the PA measurements in the lightly deformed, softer samples. Samples which have been cold rolled to hardnesses aboye about 300 KHN have sustained large deformations throughout so that the surface behavior no longer contrasts greatly with the bulk. Electropolishing the heavily cold worked specimens was found to result in a slight increase in the PA lineshape parameter. This suggests that frictional surface heating during rolling had resulted in some surface annealing in the heavily deformed samples. In addition, the changes in PA due to electropolishing the as-recelved samples are greater than the corresponding changes for the annealed samples. The implication is that the as-recefred samples had a more severely damaged surface layer than the annealed samples. This is likely since the reannealing occurred after the samples were machined to stze prior to cold roliting, resulting in the removal of surface damage created during machining. This surface damage was not removed from the as-received material prior to cold rolling and thus contributed to the $P A$ measurements made prior to electropolishing.

It was concluded that the surface layer of sectioned samples must be removed to insure significant $P A$ results and that the 


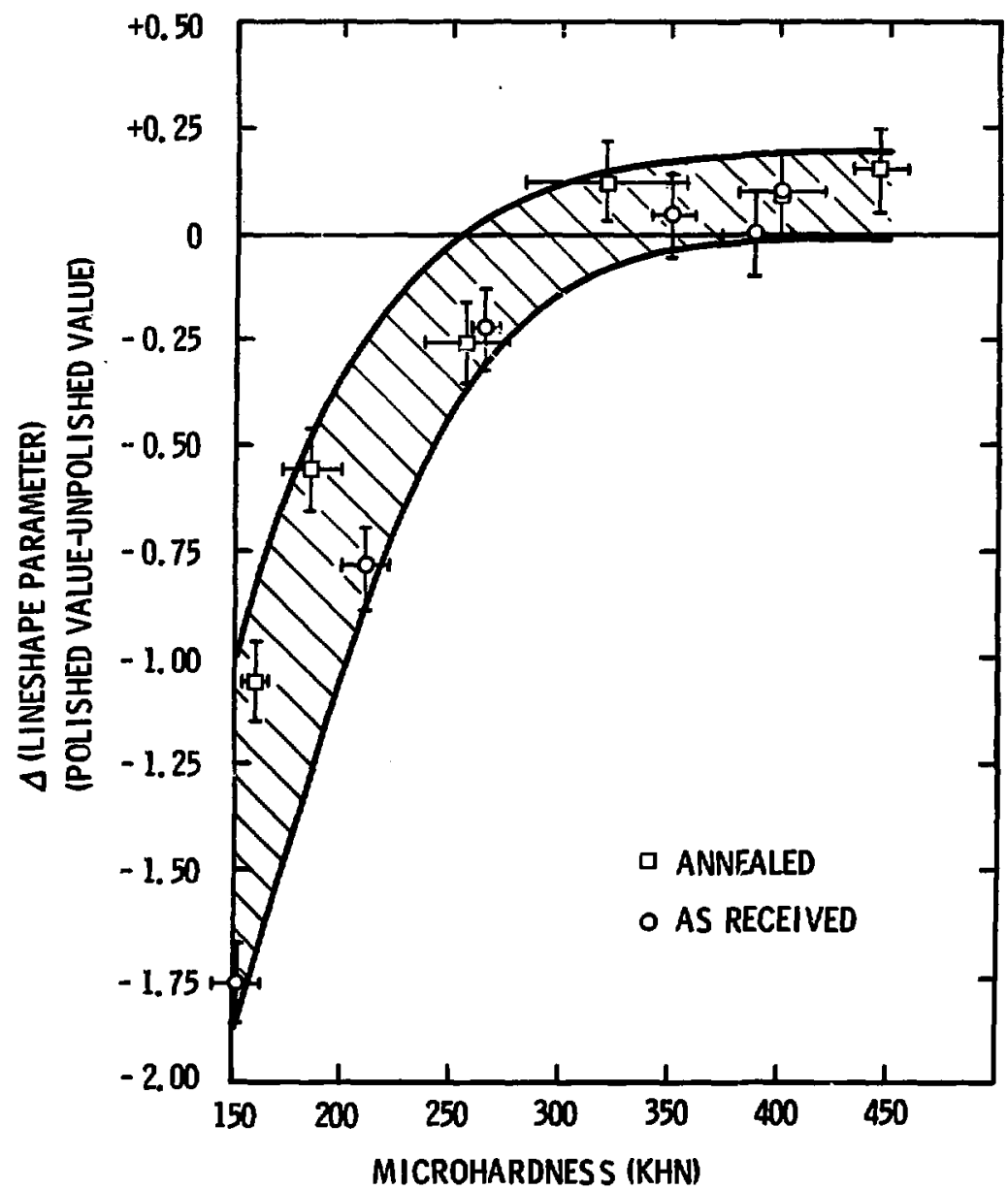

Figure 3. The change of measured positron annihilation lineshape parameter caused by removing a 125 $\mu \mathrm{m}$ surface layer, versus the microhardness in Knoop hardness number (KHN). Includes undeformed samples and samples listed in Table II. 
$22 \mathrm{Na}$ positron source used here requires that $125 \mu \mathrm{m}$ of material be removed. In future work on unsectioned specimens (see Section $V I)$ removal of surface layers will not be required between sequential PA measurements. For future practical applications, especially with higher energy positron sources, surface preparation beyond simple cleaning is not expected to be necessary.

\section{B. Cold rolled 316 stainless steel}

Figure 4 shows the measured lineshape parameter as a function of percent thickness reduction for the electropolished specimens. There is no significant difference between the annealed and as-received sets, which corresponds to the similar1ty of these two sets in microhardness behavior. The error bars represent the uncertainty limit of the counting statistics.

The $l$ ineshape parameter reaches a maximum in the vicinity of $25 \%$ cold work. The total effect is large relative to the error bars and was shown in other tests to be reproductble. Between 25 and $75 \%$ cold work a decrease of 11 neshape parameter is observed that is small but appears to be real. In contrast, microhardness was found to increase steadily during cold work, approaching a constant value after about $30 \%$ thickness reduction. Figure 5 is a cross-plot of lineshape parameter and microhardness, showing that the microhardness is not a unique function of the lineshape parameter.

Prevlous work on cold worked pure metals ${ }^{9}$ has shown that positrons are trapped at dislocations and that the effect Increases with increasing dislocation density until a saturation 


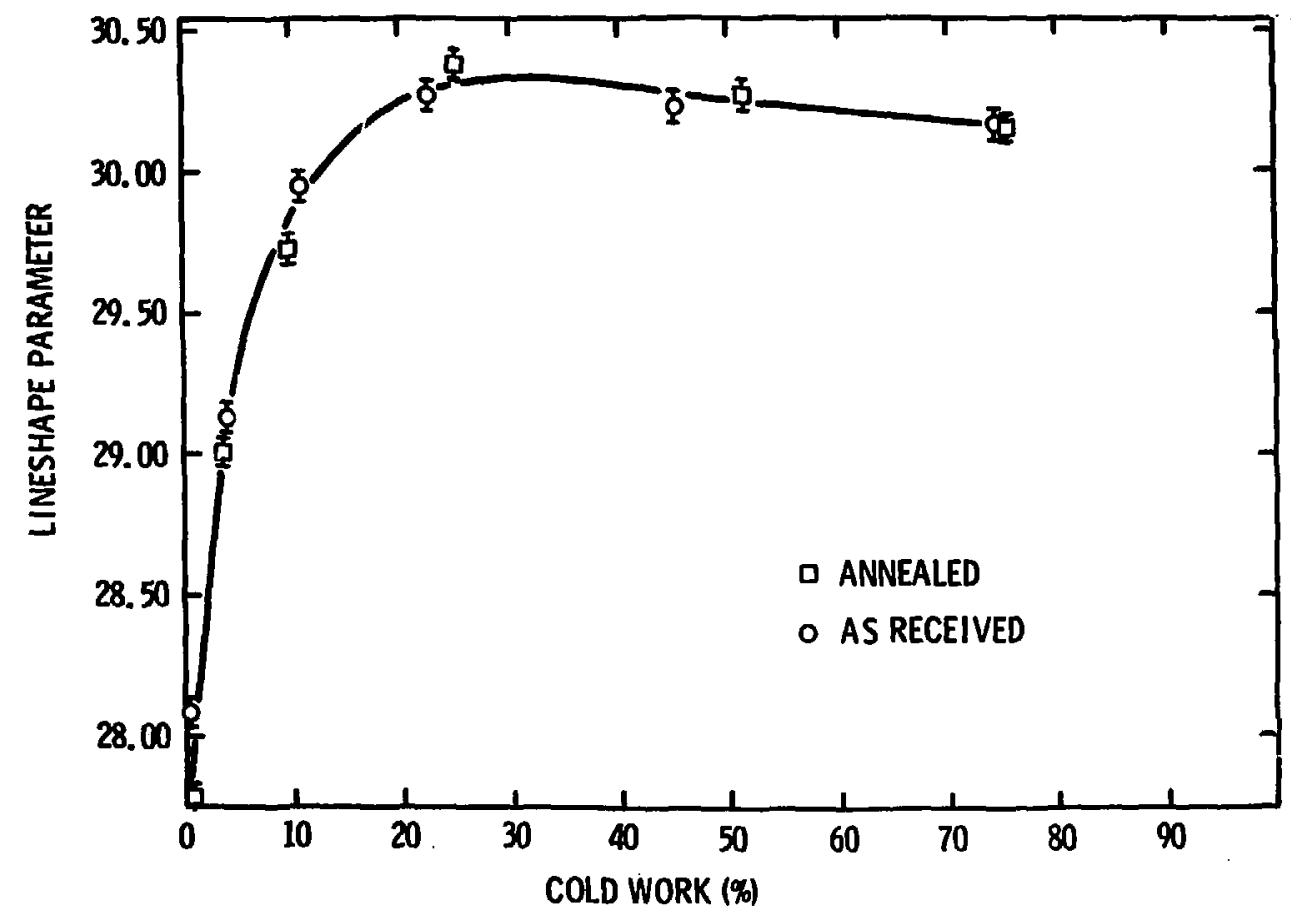

Figure 4. Positron annihilation lineshape paraneter as a function of percent thickness reduction for cold worked 316 stainless steel. 


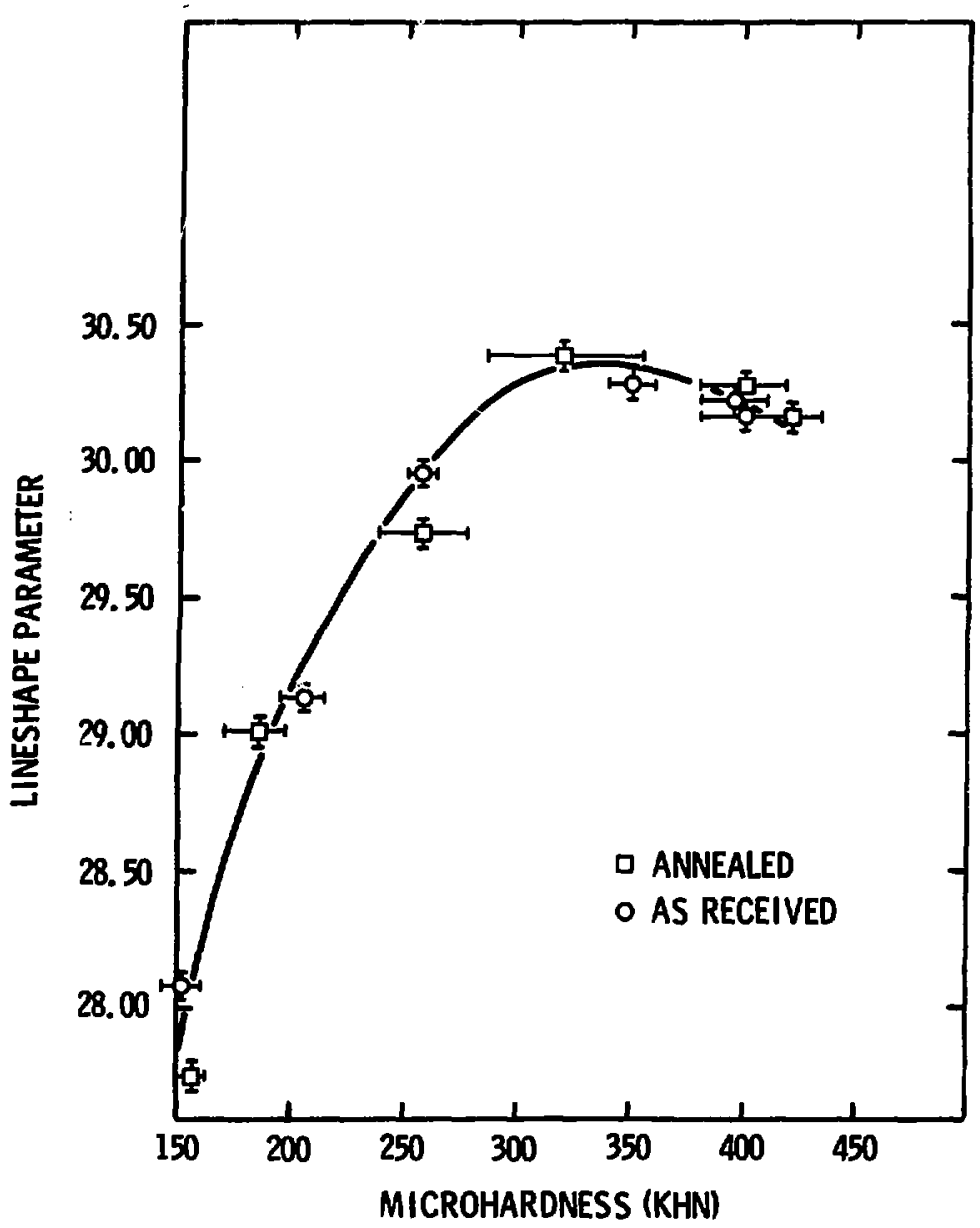

Figure 5. Positron annihilation 1 ineshape parameter as a function of microhardness in knoop hardness number (KHK) for cold worked 316 stainiess steel. 
occurs. Our results for 316 stainless steel show the same behavior as has been observed for pure metals, and the effect is large and reproducible. In addition, we observe a turnover in the lineshape parameter values at high deformations that is not seen in the microhardness.

C. Low-cycle fatigue of 316 stainless steel

An initial objective of the measurements on fatigue cycled samples was to determine how large an effect could be observed by $P A$, and to follow the effect all the way to failure. For this reason we began with room-temperature tests at relatively high cyclic total strain amplitudes of $\pm 0.90 \%$.

Results in Figure 6 show that for the higher strain ampi1tude, saturation of the PA effect has occurred after 10 cycles. Whether or not the dip at 370 cycles is real cannot be ascertained at this time, because the data do not represent the history of a single specimen to fallure. Thus specimen-tospecimen variations may be the cause of this smaller effect. Figure 7 shows a series of transmission electron micrographs from specimens cycled to varying numbers of cycles at $\Delta \varepsilon= \pm 0.90 \%$. Significant variations in dislocation substructure were observed within each specimen; the three micrographs included for each deformation history represent the range of microstructures that were observed. This variation is antictpated in fatigue tests on polycrystalline materials. These samples had grain size of 10 to $20 \mu$ with the cross section of the fatigue specimens containing several hundred grains. 


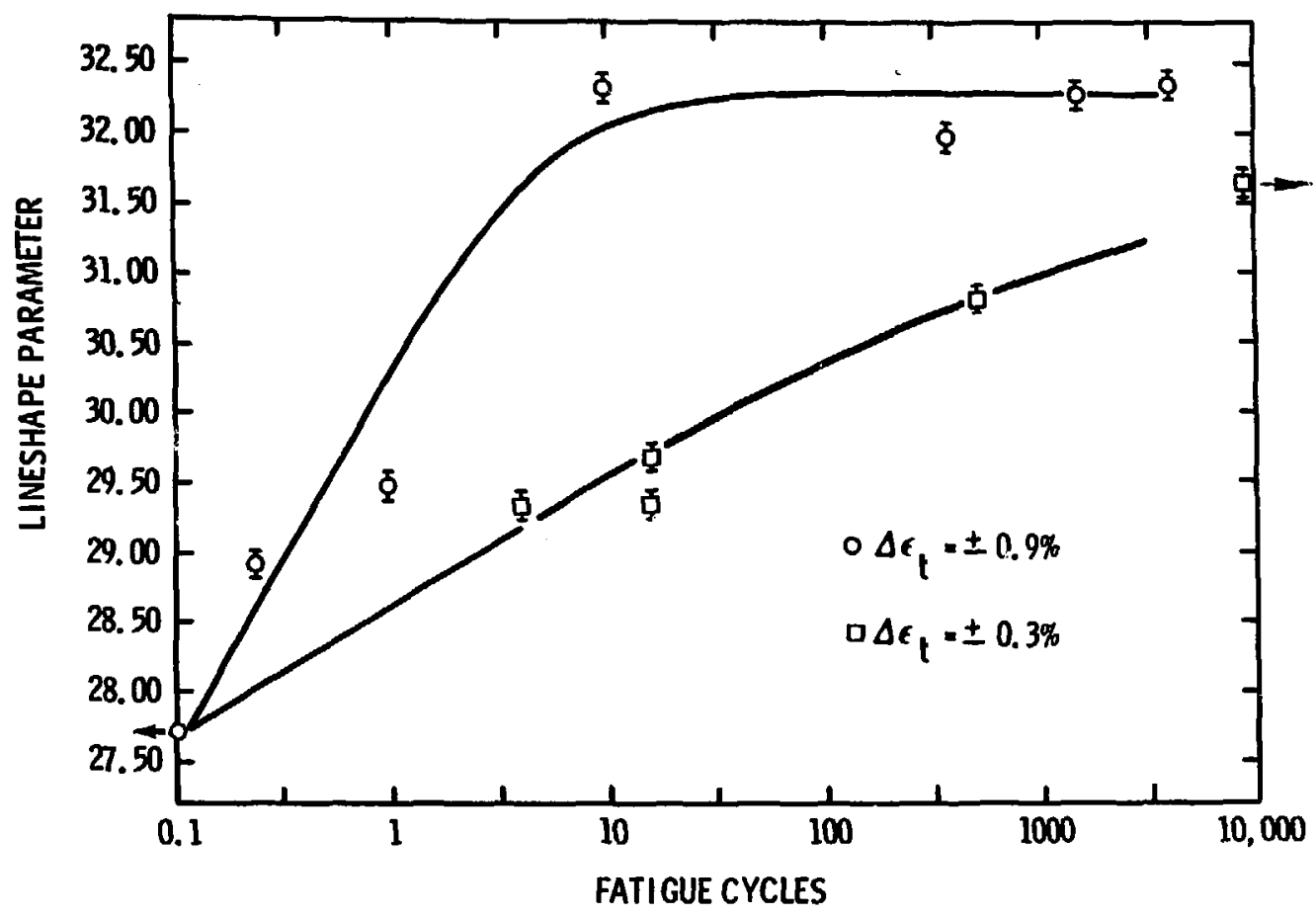

Figure 6. Positron annihilation lineshape parameter as a function of number of fatigue cycles at two different cycific strain amplitudes for 316 stainless steel fatigued at room temperature. The point with arrow to left corresponds to 0 cycles; point with arrow to right corresponds to 47143 cycles. 
ANNEALED

1 CYCLE
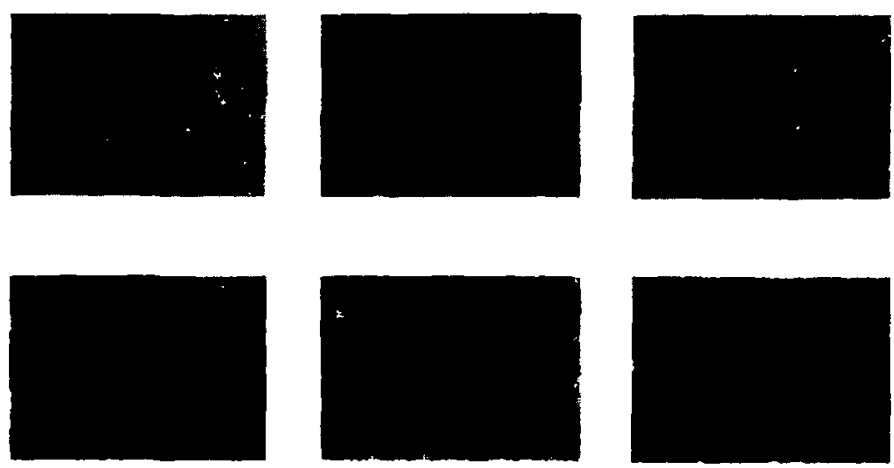

10 CYCLES
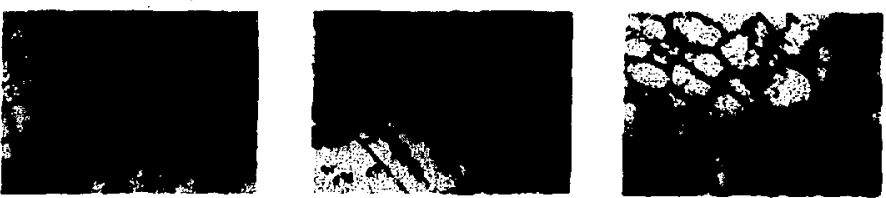

370 CYCLES
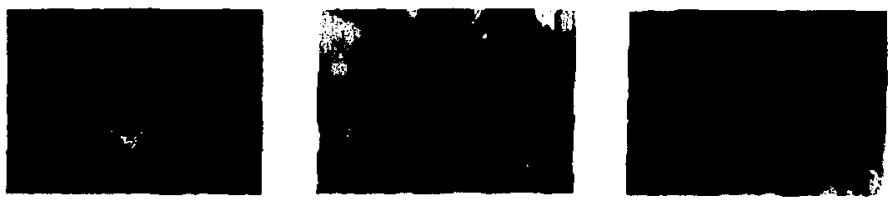

3700 CYCLES

(FAILURE)

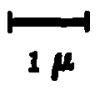

Figure 7. Transmission electron micrographs of 316 stainless steel samples after various numbers of fatigue cycles at $\pm 0.9 \%$ cyclic strain amplitude. 
316 stainless steel is a single phase face centered cubic structured alloy in which changes in dislocation substructure are the only changes occurring during deformation.

The substructure evolution shown in Figure 7 which takes place during cycing is consistent with the processes described by Kuhlmann-Hilsdorf and Latrd. ${ }^{10}$ Most of the previous work on cyclic deformation of FCC metals has involyed pure copper and solid solution copper alloys; however, the available results for austenitic stainless steels ${ }^{11}$ are broadly similar.

One complete cycle results in a clear increase in dislocation density from an annealed yalue of $8 \times 10^{8} \mathrm{~cm}^{-2}$ to $7 \times 10^{9} \mathrm{~cm}^{-2}$. These dislocations are arranged in patches which contain numerous dipoles. Continued cycling produces the markedly different substructures shown for the 10 cycle specimen. The first micrograph depicts heayy dislocation loop patches in what is described as a yeining structure. ${ }^{10}$ The second micrograph shows a veining structure breaking into persistent silp bands of dislocations (PSB's). A well formed PSB structure is evident in the last micrograph. Even though there exists this large variation in substructure within the 10 cycle specimen, each represents a large increase in dislocation density over the I cycle specimen. Further cycling results in continued substructure changes. The final step in the process is the formation of dislocation cell structure. After 370 cycles, dislocation cells have formed throughout most of the sample. The second iffcrograph does indfcate that a few regions remain in a vining structure. Comparison of the specimens cycled 
10 and 370 times indicates that the dislocation density has increased slightly. Cycling to failure ( 3700 cycles) does not result in any change in cell size or shape but the contrast effects in the micrographs show that a lattice mismatch between adjacent cells has accumulated during continued cycling. As the first micrograph of the 3700 cycles series shows, there continue to be variations in substructure within single specimens, even at failure.

The trend in dislocation density throughout this progression in substructure development is a monotonic increase from no deformation up to 10 cycles followed by a slight decrease as the cell structure forms and stabilizes after seyeral hundred cycles. For the remainder of the sample life, the dislocation density remains essentialiy constant.

Figure 6 shows that the PA 1 ineshape parameter appears to follow these changes in dislocation density reasonably well. The peak in lineshape parameter at 10 cycles agrees with the qualitative disiocation density observations from Figure 7 . These photomicrographs also imply that the lineshape parameter would decrease slightly after 370 and greater cycles. As previously discussed, any such behavior may be obscured by specimento-specimen variations.

The substructure evolution which occurs during cycling at $\Delta \varepsilon= \pm 0.9 \%$ is driven by the increases in stress level which occur during the first 15 to 20 cycles. ${ }^{10}$ When strain controlled fatfgue tests are conducted at lower strain amplitudes, such as $\pm 0.3 \%$, cyclic hardening occurs, just as it does at $\Delta \varepsilon= \pm 0.9 x$, 
but the saturation stress level is lower at the lower strain range, $262 \mathrm{MPa}$ compared to $351 \mathrm{MPa}$. The result of this difference in saturation stress level is a difference in substructure. 10 Cells may not form at this lower stress level and if cells do form, the cell size will be larger. ${ }^{12}$ The measured 1 ineshape parameter values indicate that the dislocation density remains lower when the strain amplitude is $\pm 0.3 \%$ than when it is $\pm 0.9 \%$ (Figure 6). TEM examination is currently underway to establish the substructures of the lower strain range samples. Work by Chopra and Gowda ${ }^{13}$ on $\alpha$-iron has shown that the rate of substructure development is retarded at low strain amplitudes. They found that for low strains the structure began to develop at a higher percentage of the ultimate fatigue life than at higher strains. This suggested that for 316 steel as well the saturation values of dislocation density and of $P A$ lineshape parameter might occur at a higher percentage of fatigue life at lower strain amplitudes.

Figure 6 does show, in fact, that for $\pm 0.3 \%$ strains the increase of PA lineshape parameter as a function of the number of fatigue cycles is more gradual. No specimens were cycled to fallure at $\Delta E= \pm 0.3 \%$; but the last measurewent point of 47,143 cycles, corresponding to an estimated $1 / 3$ to $1 / 2$ of fatigue 11 fe, shows that the lineshape parameter saturation occurs at a much higher fraction of fatigue life than for larger strain ranges.

The finding that the PA effect depends strongly on cyclic strain amplitude is important to the application of PA as a 
nondestructive evaluation technique. Earlier PA studies of fatigue on $\mathrm{Ni}$ and $\mathrm{Ni}-\mathrm{Co}$ alloys, ${ }^{14}$ AISI 4340 steel, 15 and polycrystalline Cu${ }^{16}$ all showed saturation of the effect early in fatigue life, but were all done at high strain amplitudes. Our first results on 316 stainless steel suggest that for the lawer strains more usually encountered in the service life of a component, the bulldup of the PA effect may well be gradual enough to serve as an indicator of remaining useful $11 \mathrm{fe}$. Moreover, the extreme sensitivity $f P A$ lineshape parameter to high strains may be useful as evidence of whether a component has been subjected to a strain excursion. These points will be the subject of further investigation.

As discussed in Section I, an objective of this work is to deyelop a sensitive monitor of high temperature creep and creep/ fatigue damage. The dislocation substructures which develop during fatigue at 800 to $900 \mathrm{~K}$ are not unlike those which form during room temperature deformation, as shown by $\mathrm{Nahm}$, et al, 11 who cycled 304 stainless steel at $822 K$ and $\Delta E= \pm 1 \%$. The effects of lower strain amplitudes have not been studied but should be similar to those observed for reduced strain amplitudes at room temperature. Since both climb and cross sip processes are easier at higher temperatures, dislocation densities may be lower and the equilibrium substructure may be established sooner after high temperature deformation. The establishment of these relationships is the next goal of the current study. 


\section{v. CONCLUSIONS}

1. Our measurements have shown that PA provides a sensitive nondestructive monitor of plastic deformation caused by cold rolling and by fatigue cycling of 316 stainless steel at room temperature.

2. For fatigue cycled specimens, transmission electron microscopy indicated a correlation between the PA effect and density of dislocations in the samples.

3. The stage of fatigue life at which the PA effect saturates is a sensitive function of the strain amplitude. Our first results suggest that for low strains PA may provide a meaningful nondestructive measure of remaining useful life. The sensitivity to high strains provides a potential monitor for strain excursions.

VI. FUTURE PLANS

A series of tests is currently being conducted on 316 stafnless steel subjected to creep and fatigue damage at $866 \mathrm{~K}(1100 \mathrm{~F})$, and PA and TEM will be performed on the spectmens. The creep tests will be carried to several different fractions of 1 ife, with the longest tests lasting 2000 hours. Fatigue tests are being run at a total strain amplitude of $\pm 0.25 \%$ and some will have tenstle or compressive hold periods.

In order to minimize the surface effects discussed in Section IV.A., future tests will be done with a ${ }^{68}$ Ge positron 
source in place of the ${ }^{22} \mathrm{Na}$ source used so far. The depth of penetration positrons from ${ }^{68} \mathrm{Ge}(\sim 180 \mu \mathrm{m})$ is approximately six times that of positrons from ${ }^{22} \mathrm{Na}$, so that effects due to surface working or surface irregulartties will be reduced greatly.

An apparatus is being assembled that will enable tests to be carried out on mechanfcal test specimens directly without sectfoning them. It w11l then be possible to scan one specimen at certain intervals of fatigue life until fallure, as well as to look for inhomogenetties in samples. The system wlll include a remote positron source 6,7 and a "labeling" technique 17 to reduce background.

\section{ACKNOWLEDGEMENT}

We thank J. C. Banks for assistance with the positron annihilation measurements, and C. R. Hills for performing the transmission electron microscopy. 


\section{REFERENCES}

1. R. N. Hest, Adv. Physics 22, 263 (1973).

2. W. Triftshäuser, in Festkörperprobleme (Advances in Solid State Physics), J. H. Quelsser, ed., (Pergamon/Vieweg. Braunschweig 1975), Vo1. 15, p. 381.

3. W. B. Gauster, J. Vac. Sci. Tech. (in press).

4. S. Berko and J. C. Erskine, Phys. Rev. Lett. 19, 307 (1967).

5. J. C. Grosskreutz and W. E. Millett, Phys. Lett. 28A, 621 (ig69).

6. C. F. Coleman and A. E. Hughes in Research Techniques in Nondestructive Testing, R. S. Sharpe, ed., (Academic Press, New York and London 1977) Vol. 3.

7. C. F. Coleman, F. A. Smith, and A. E. Hughes, UKAEA Harwell Report AERE-R8551 (1976).

8. W. R. Wampler and W. B. Gauster, J. Phys. F: Metal Phys. 8 , Li(1978).

9. See, for example, B. T. A. Mckee, S. Saimoto, A. T. Stewart, and M. J. Stott, Can. J. Phys. 52, 759 (1974).

10. D. Kuhlmann-W1lsdorf and C. Laird, Mat. Sci. Engr. 27, 137 (i977).

17. H. Mahm, J. Moteff, and D. R. Diercks, Acta Met., 25, 107 (i977).

12. H. J. Mcqueen, Met. Trans. A, 8A, 807 (1977).

13. O. K. Chopra and C. V. B. Gowda, Phil. Mag. 30, 583 (1974).

14. K. G. Lynn, C. M. Wan, R. W. Ure, and J. G. Byrne, Phys. Stat. So1. (a) 22, $731(1974)$.

15. K. G. Lynn and J. G. Byrne, Met. Trans. A, 7A, 604 (1976).

16. J. G. Byrne, P. Alexopoulos, F. Alex, T. D. Hadnagy, R. Waki, G. R. Miller, and $R$. W. Ure, in Proceedings of the Fourth Internationai Conference on Positron Annihilation, Helsingdr, Denmark. August 1976 (unpublished).

17. I. K. Mackenzie, P. C. Lichtenberger, and J. L. Campbe11, Can. J. Phys. 52, 1389 (1974). 